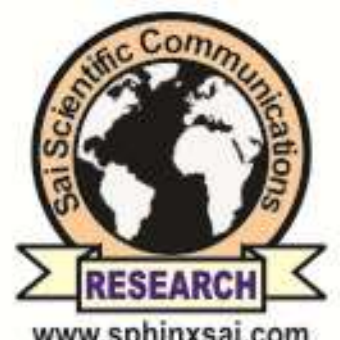
International Journal of ChemTech Research
CODEN (USA): IJCRGG, ISSN: 0974-4290, ISSN(Online):2455-9555

Vol.12 No.03, pp 64-71,

2019

\title{
Spectroscopy and structural study of Oxidative degradation Congo Red Dye under sunlight using $\mathrm{TiO}_{2} / \mathrm{Cr}_{2} \mathrm{O}_{3}-\mathrm{CdS}$ nanocomposite
}

\author{
Zaid Hamid Mahmoud $^{1 *}$ and Rasoul Fakhrie Khudeer $^{2}$ \\ ${ }^{1}$ Department of chemistry, college of science, Diyalauniversity, Diyala \\ ${ }^{2}$ Department of Energy Salah Al_Din2, Energy Authority, Refineries company, \\ ministry of oil, Baghdad
}

\begin{abstract}
In this study, the photoactive degradation of $\mathrm{TiO}_{2} / \mathrm{Cr}_{2} \mathrm{O}_{3}-\mathrm{CdS}$ has been investigated in Congo red dye under sunlight. The nanoparticles of catalyst were successfully synthesized using photolysis method. The X-ray diffraction (XRD), UV-visible spectroscopy and Raman spectrum were used to characterized of nanocomposite of $\mathrm{TiO}_{2} / \mathrm{Cr}_{2} \mathrm{O}_{3}-\mathrm{CdS}$. Several parameters were examined to get the optimum condition for degrading of dye and prove the activity of the catalyst. The mechanism of degradation was suggested by using mass spectrum.
\end{abstract}

Keywords : photolysis, degradation, CdS, nanoparticles.

\section{Introduction}

Industrial dyestuffs consider one of the major groups that constitute a growing environmental danger. A massive amount of the dyes such as Azo and non-stable dye found in water waste that created by the textile industries. Azo dye represents the most abundant type of these dyes. ${ }^{[1,2]}$ The danger comes from discharged these dyes that have a different chemical structure in water waste and consider a highly carcinogenic. ${ }^{[3]}$ To remove these dye, physical and chemical methods used, but it doesn't resolve the problem; because transfer it from a shape to another or phase ${ }^{[4-7]}$ among these methods, heterogeneous photocatalyst technology used as a destructive method by total mineralization of the dyes. $\mathrm{TiO}_{2}$ electrode utilized in 1972 by Honda and Fujishima to split the water photolysis and this method was developed to convert solar energy and to recycle the pollutants in water and used it as a source of energy. ${ }^{[8-10]}$ The result of power oxidation, $\mathrm{TiO}_{2}$ utilized in many applications and the most important is it used as photocatalyst for degrading the pollutants under sunlight. ${ }^{[11-13]}$ Titanium oxide has two phase rutile and anatase with band gap 3.0 and $3.2 \mathrm{eV}$ respectively. ${ }^{[14-16]} \mathrm{A}$ series of studies and researches have been begun to study about increasing the efficiency of $\mathrm{TiO}_{2}$ to degrade the organic and dyes pollutant by doping it by $\mathrm{Cr}_{2} \mathrm{O}_{3}, \mathrm{SiO}_{2}, \mathrm{ZnO}$ and utilize another compound such $\mathrm{CdS}$ to increase the adsorption capacity of dyes. ${ }^{[17-21]}$ In this paper prepared $\mathrm{TiO} 2$ using UV-irradiation ${ }^{[22-24]}$ and modified surface with $\mathrm{Cr}_{2} \mathrm{O}_{3}$ 
prepared and photolysis. Besides dispersed of $\mathrm{CdS}$ nanoparticles on the surface of $\mathrm{TiO}_{2} / \mathrm{Cr}_{2} \mathrm{O}_{3}$ using the hydrothermal method to increase the surface area of nanoparticles. Among the nanocomposite, the $\mathrm{TiO}_{2} / \mathrm{Cr}_{2} \mathrm{O}_{3}-$ $\mathrm{CdS}$ were appropriate dye elected in Congo red dye reaction carried out in direct sunlight.

\section{Materials and method}

\subsection{Materials}

All materials that used to prepare the nanocomposite used without purification, and supplied by the Merck company, such as titanium tetrachloride $\left(\mathrm{TiCl}_{4}\right)$, chromium nitrate $\left(\mathrm{Cr}\left(\mathrm{NO}_{3}\right)_{3} \cdot 9 \mathrm{H}_{2} \mathrm{O}\right)$, sodium sulfide $\left(\mathrm{Na}_{2} \mathrm{~S} .9 \mathrm{H}_{2} \mathrm{O}\right)$ and $\left(\mathrm{Cd}\left(\mathrm{NO}_{3}\right)_{2} \cdot 4 \mathrm{H}_{2} \mathrm{O}\right)$ were used as source materials to prepare the nanocomposite. While the ethanol used as a solvent to make the solutions of salts and distilled water for Dye to achieve the activity of nanoparticles, Congo red dye $\left(\mathrm{C}_{32} \mathrm{H}_{22} \mathrm{~N}_{6} \mathrm{Na}_{2} \mathrm{O}_{6} \mathrm{~S}_{2}\right)$ utilized, the hydrochloric acid ( $\left.\mathrm{HCl}\right)$ and sodium hydroxide $(\mathrm{NaOH})$ was used to modify the $\mathrm{pH}$ of the Dye solution.

\subsection{Synthesis of $\mathrm{TiO}_{2} / \mathrm{Cr}_{2} \mathrm{O}_{3}-\mathrm{CdS}$ nanocomposite}

$\mathrm{TiO}_{2} / \mathrm{Cr}_{2} \mathrm{O}_{3}$ nanocomposite was fabricated using the photolysis method like the following: $0.01 \mathrm{~mol}$ of each Titanium chloride and chromium chloride prepared in two beakers separately. These solutions irradiated until metal hydroxide forms ( $2 \mathrm{hr}$ for titanium salt and $3 \mathrm{hr}$ for chromium chloride). The two freshly precipitates mixed and stirred for $2 \mathrm{hrs}$, then burned at $400 \mathrm{C}$. The two components of cadmium nitrate and sodium sulfide with a ratio (0.5:1.5) mole were mixed and transferred to the autoclave. Then, $1 \mathrm{gm}$ of $\mathrm{TiO}_{2} / \mathrm{Cr}_{2} \mathrm{O}_{3}$ nanocomposite was added to the mixture and kept the temperature at $150 \mathrm{C}$. After the reaction, the formed precipitate was washed using ethanol, acetone and distilled water three times and dried it.

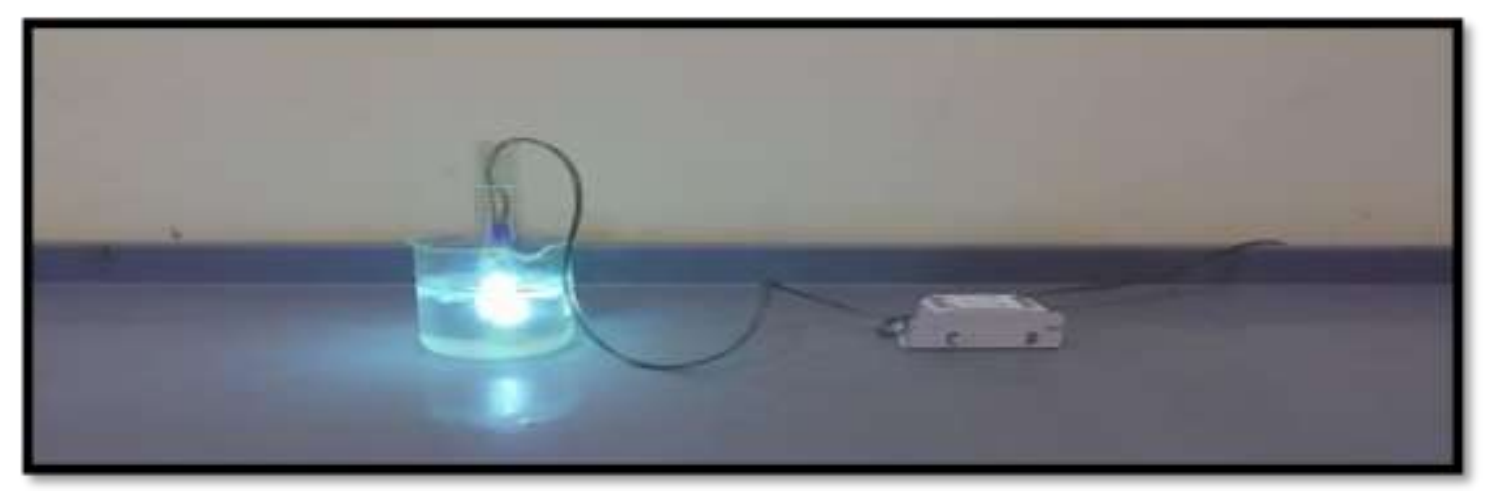

Figure. 1: Irradiation system

\subsection{Photocatalyticmeasurements}

The Photocatalytic activity of $\mathrm{TiO}_{2} / \mathrm{Cr}_{2} \mathrm{O}_{3}-\mathrm{CdS}$ nanocomposite investigated via the degradation of Congo red (CR) under direct sunlight. $1000 \mathrm{mg} / \mathrm{L}$ of CR dye prepared as a stock solution by dissolving $0.5 \mathrm{~g}$ in $0.5 \mathrm{~L}$ distilled water and diluted it to the desired concentration. The mixture of nanocomposite and dye was stirred in dark region for $30 \mathrm{~min}$ before irradiation to maintain adsorption the dye on the surface of the nanocomposite. The ratio of remove color for dye was determined using UV-spectrophotometer at a 502nm wavelength to get the optimal condition for removing the dye, and many experiments worked such $\mathrm{pH}$ of the dye solution, an initial concentration of the dye and catalyst and the time of irradiation.

\section{Result and discussion}

\subsection{XRD}

For examined the structure, the XRD pattern of $\mathrm{TiO}_{2} / \mathrm{Cr}_{2} \mathrm{O}_{3}$ and $\mathrm{TiO}_{2} / \mathrm{Cr}_{2} \mathrm{O}_{3}$ - $\mathrm{CdS}$ nanocomposite demonstrated in figure $2 \mathrm{~A}$ and $2 \mathrm{~B}$. In figure $1 \mathrm{~A}$, many peaks assigned to $\mathrm{Cr}_{2} \mathrm{O}_{3}$ particles located at $2 \theta=24.5$, $26.3,33.6$ and 36.1 with a rhombohedral structure while two peaks centered at value 26.5 and 43.7 back to CdS nanoparticles and all the product are in agreement with (JCPDS no.38-1479 and 65-8193) respectively. The 
results showed highly crystalline for particles, and it's useful for utilizing as a catalyst for photocatalytic application. The size of the particles was calculated using Scherer Eq. 1.

$\mathrm{D}=0.9 \square / \square \cos \theta$

The size was calculated using the high-intensity peak for $\mathrm{TiO}_{2} / \mathrm{Cr}_{2} \mathrm{O}_{3}$ and $\mathrm{TiO}_{2} / \mathrm{Cr}_{2} \mathrm{O}_{3}-\mathrm{CdS}$. The results appeared crystal size value $17.43 \mathrm{~nm}$ for $\mathrm{TiO}_{2} / \mathrm{Cr}_{2} \mathrm{O}_{3}$ and $25.41 \mathrm{~nm}$ for $\mathrm{TiO}_{2} / \mathrm{Cr}_{2} \mathrm{O}_{3}-\mathrm{CdS}$.
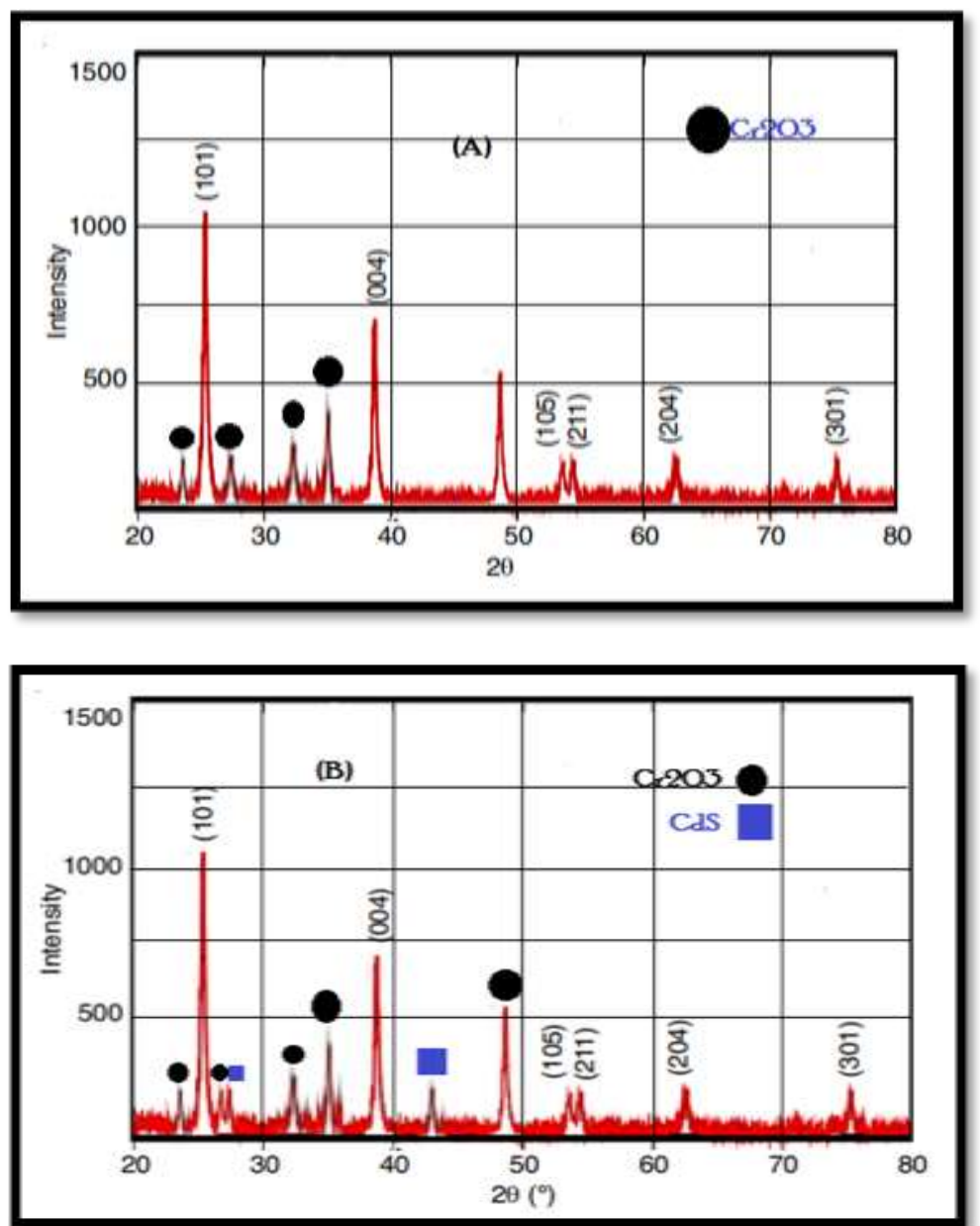

Fig.2 XRD of $\mathrm{TiO}_{2} / \mathrm{Cr}_{2} \mathrm{O}_{3}(\mathrm{~A})$ and $\mathrm{TiO}_{2} / \mathrm{Cr}_{2} \mathrm{O}_{3}-\mathrm{CdS}(\mathrm{B})$

\subsection{UV-Vis spectra}

For the determine the optical spectra of nanoparticles synthesized, the UV-Vis analysis was carried out. The UV-Vis spectra of $\mathrm{TiO}_{2} / \mathrm{Cr}_{2} \mathrm{O}_{3}$ and $\mathrm{TiO}_{2} / \mathrm{Cr}_{2} \mathrm{O}_{3}-\mathrm{CdS}$ was showed at fig 3. The doping $\mathrm{Cr}_{2} \mathrm{O}_{3}$ and $\mathrm{CdS}$ on $\mathrm{TiO}_{2}$ play main role in increase the adsorptionintensity towards the visible light as appearing in the results because the electron holes of $\mathrm{TiO}_{2} / \mathrm{Cr}_{2} \mathrm{O}_{3}$ transfer from the valence band to the conduction band of $\mathrm{CdS}$ and causes a red shift. 


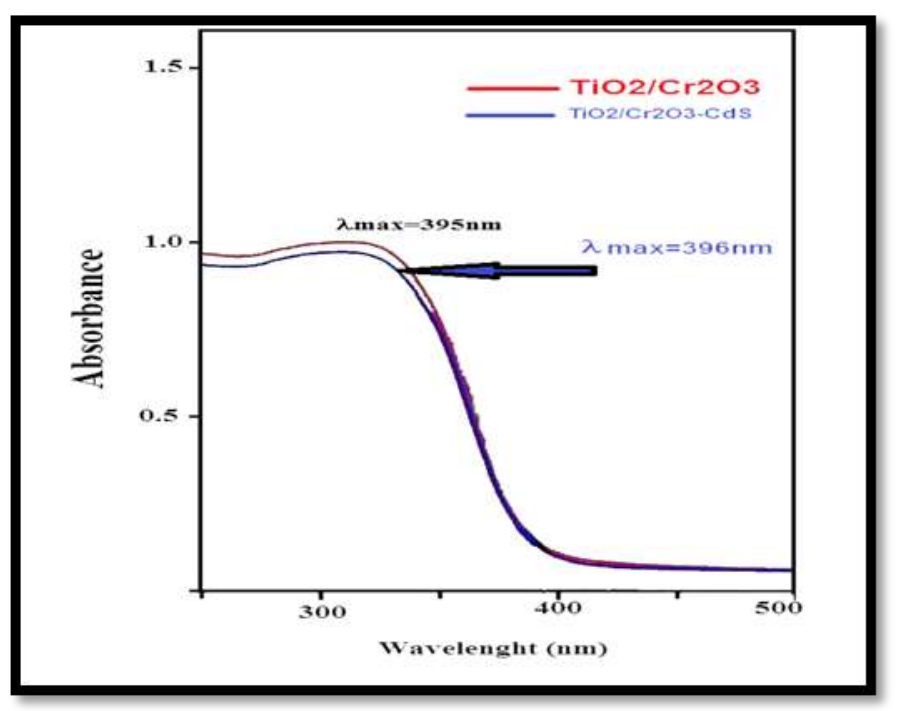

Fig. 3: UV-Vis spectra of $\mathrm{TiO}_{2} / \mathrm{Cr}_{2} \mathrm{O}_{3}$ and $\mathrm{TiO}_{2} / \mathrm{Cr}_{2} \mathrm{O}_{3}-\mathrm{CdS}$

\subsection{Raman spectrum}

To investigate the crystalline phase and the effect of doping CdS, the spectra of Raman was carried out as shown in fig 4. The results appeared five peaks located at 144, 196, 635, 516 and 396 assigned to symmetricEg, $\mathrm{A}_{2} \mathrm{~g}$ and $\mathrm{B}_{1} \mathrm{~g}$ for anatase phase respectively, and two peaks at 300 and $602 \mathrm{~cm}^{-1}$ back to a strongly attach of $\mathrm{CdS}$ particles in the $\mathrm{TiO}_{2} / \mathrm{Cr}_{2} \mathrm{O}_{3}$ nanocomposite. The results obtained good crystalline nature of nanocomposite. ${ }^{[25,26]}$

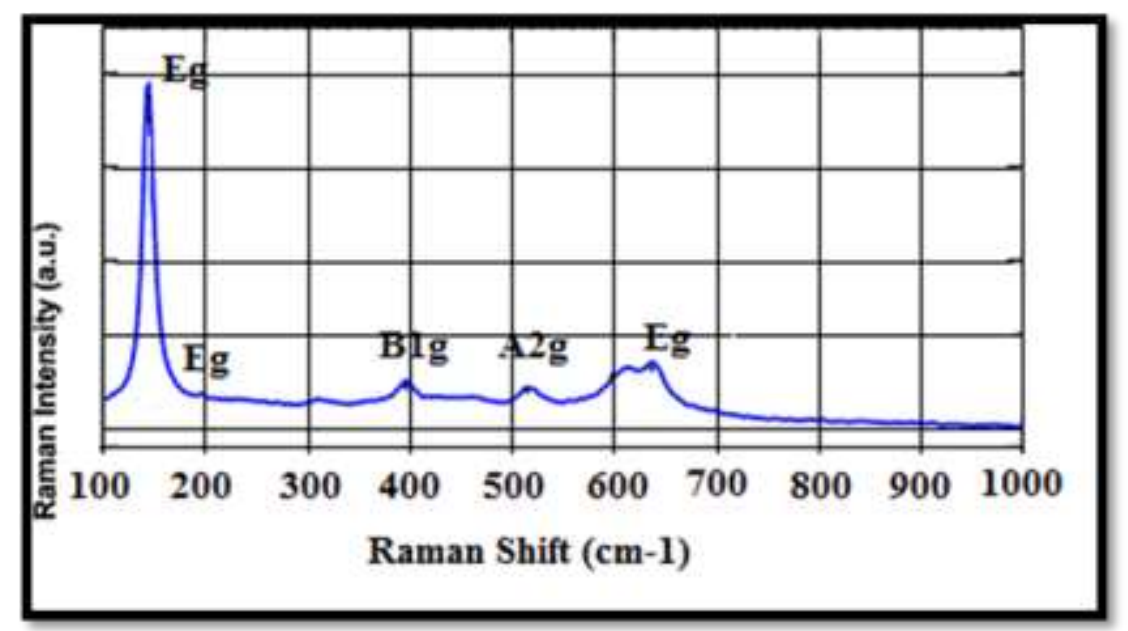

Fig 4. Raman spectra of $\mathrm{TiO}_{2} / \mathrm{Cr}_{2} \mathrm{O}_{3}-\mathrm{CdS}$ nanocomposite

\subsection{Effect of catalyst dosage and irradiation time on degradation of Congo red}

\subsubsection{Effect of catalyst dosage}

For investigating the effect of catalyst dosage on degradation the $\mathrm{CR}$ dye, several amount of $\mathrm{TiO}_{2} / \mathrm{Cr}_{2} \mathrm{O}_{3}$-CdS between $(0.02$ to $0.2 \mathrm{~g})$ was added to $(20 \mathrm{mg} / \mathrm{L}) \mathrm{CR}$ dye solution and stirred with irradiating for $30 \mathrm{~min}$ as shown in fig 5.The results showed the ratio of degradation increase with increasing the amount of catalysts from 0.02 to $0.1 \mathrm{~g}$ due to increase the generation rate of free radical that attack the dye while, the higher amount appeared negative effect on degradation. The interpretation of this is increasing the obscurity of solution with increasing the dosage although an effective site increase, but the sunlight penetration decrease and hence, the degradation efficiency reduce or the reason back to the agglomeration of particles and this causes the canceled of effective site. ${ }^{[27,28]}$ 


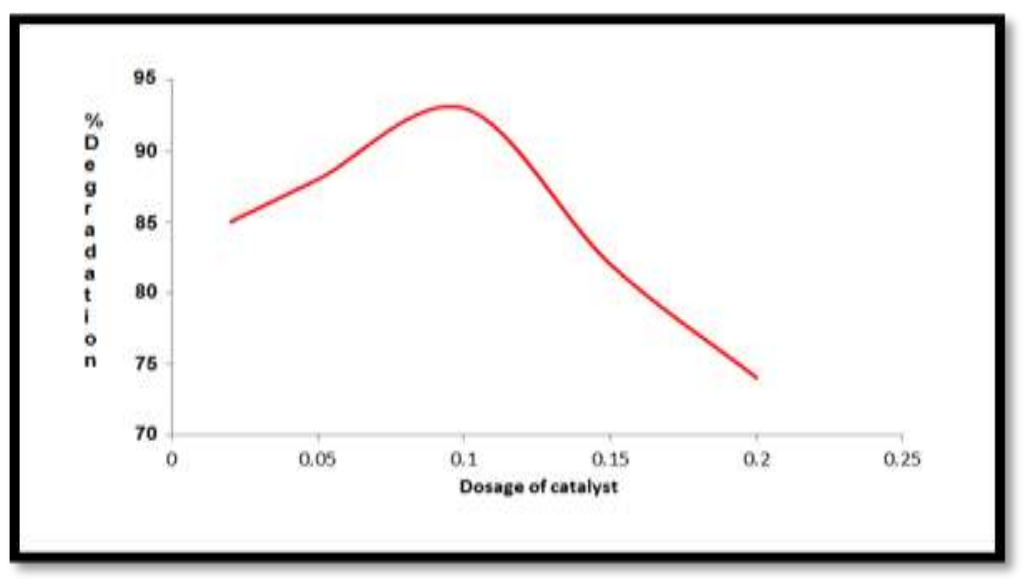

Fig 5.Effect of catalyst dosage on degradation of $\mathrm{CR}$ dye. Vol solution $=20 \mathrm{ml}, \mathrm{pH}=2.5$; irradiation time $=$ $30 \mathrm{~min}$; con of dye $=20 \mathrm{ppm}$.

\subsubsection{Effect of irradiation time}

The figure 6 showed the effect of irradiation time on degradation of CR dye. The absorbance value that corresponding to $502 \mathrm{~nm}$ and the color of the solution were decreased with increasing the time of irradiation and the reaction complete in $30 \mathrm{~min}$ as a result showing. The result obtained the rate of reaction decreased with increasing the time due to the reaction following first order and the competition for degradation between intermediate product and reactant or the difficulty converting the nitrogen atom to oxidizing nitrogen compound and short the life time of catalyst because congregation the degradation materials on the effective sites of catalyst. ${ }^{[29]}$

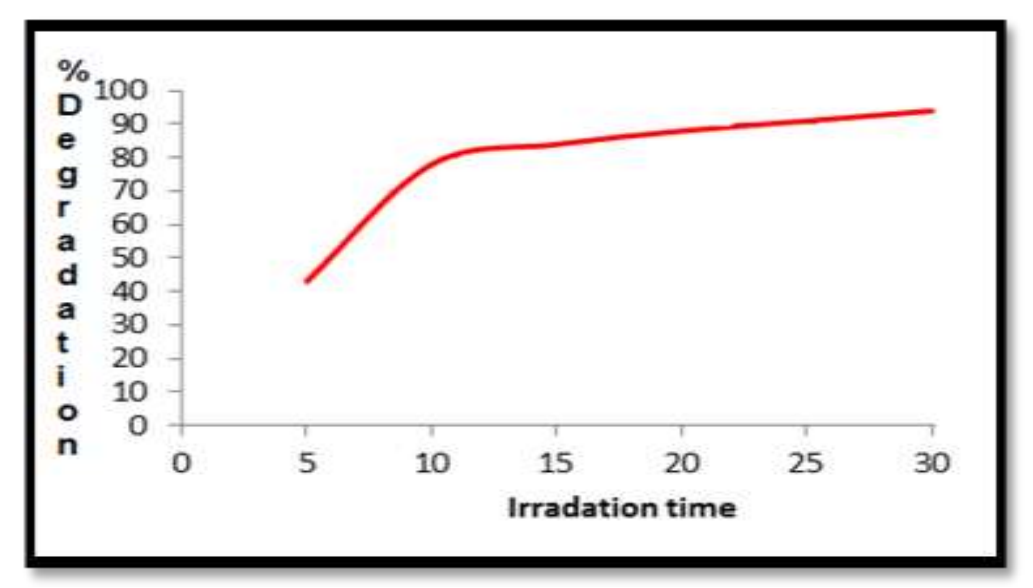

Fig 6.Effect of irradiation time on $\%$ degradation of $\mathrm{CR}$ dye. Vol solution $=20 \mathrm{ml}$; $\mathrm{pH}=2.5$; Conc. of dye = 20ppm; catalyst dosage $=0.1 \mathrm{~g}$.

\subsubsection{Effect of $\mathrm{pH}$}

The $\mathrm{pH}$ value of solution is a very important factor due to its effect on the charge of catalyst and adsorbability of CR dye on the catalyst surface. ${ }^{[30]}$ according to report the isoelectronic point of $\mathrm{TiO}_{2}$ is $6.25^{[31]}$ and hence, at different value of the solution the following expression may be occurring:

$$
\begin{aligned}
& \mathrm{TiOH} / \mathrm{Cr}_{2} \mathrm{O}_{3}-\mathrm{CdS}+\mathrm{H}^{+} \rightarrow \mathrm{TiOH}^{+2} / \mathrm{Cr}_{2} \mathrm{O}_{3}-\mathrm{CdS} \\
& \mathrm{TiOH} / \mathrm{Cr}_{2} \mathrm{O}_{3}-\mathrm{CdS}+\mathrm{OH}^{-} \rightarrow \mathrm{TiO}^{-1} / \mathrm{Cr}_{2} \mathrm{O}_{3}-\mathrm{CdS}
\end{aligned}
$$

According to the $\mathrm{pH}$ isoelectronic point, the charge of surface negative when the $\mathrm{pH}$ value $<6.25$ and positive when it $>6.25$. As appear in figure 7, the result shows the efficiency of degradation increase with decreasing the value of $\mathrm{pH}$. This could be demonstrated that $\mathrm{CR}$ dye is a binuclear aromatic ring with negative 
charge which works as a Lewis base and can easily adsorbed by Lewis acid which is $\mathrm{TiO} 2 / \mathrm{Cr} 2 \mathrm{O} 3-\mathrm{CdS}$ that have the positive charge on it surfaced.While, at alkaline medium, the repulsion force between the negative charge of the ring and the surface negative of catalyst play main role in decreasing of efficiency. ${ }^{[32]}$

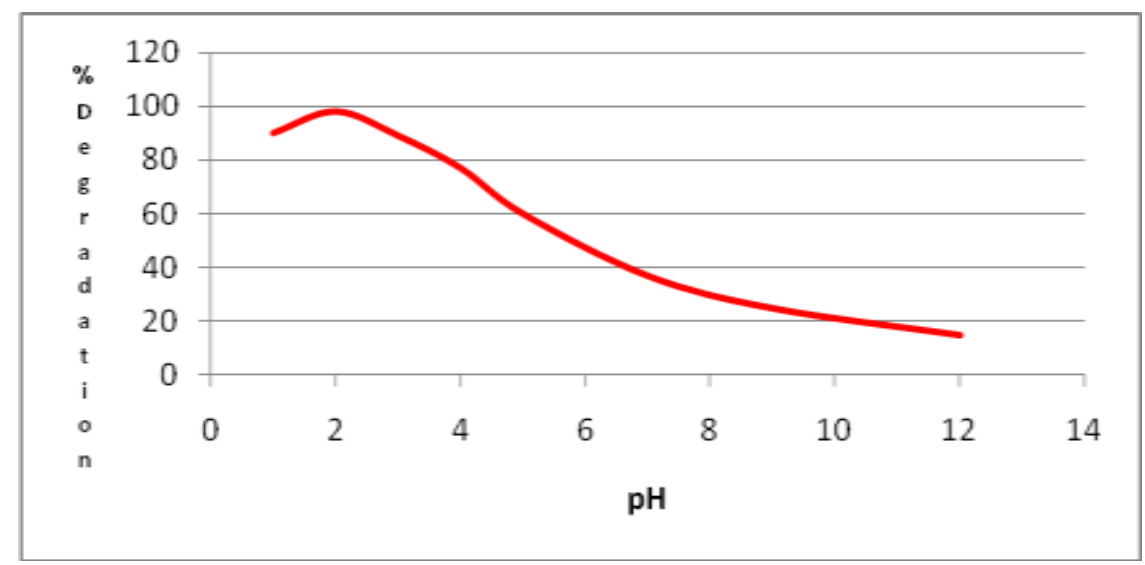

Fig.7 Effect of $\mathrm{pH}$ on $\%$ degradation of $\mathrm{CR}$ dye. Vol solution $=20 \mathrm{ml}$; Conc. of dye $=20 \mathrm{ppm}$; catalyst dosage $=0.1 \mathrm{~g}$.

In order to expand our vision about the degradation of CR dye, the MS analysis was carried out. Depending on $\mathrm{m} / \mathrm{z}$ values, the mechanism and intermediate product suggested and are shown in figure 8 .

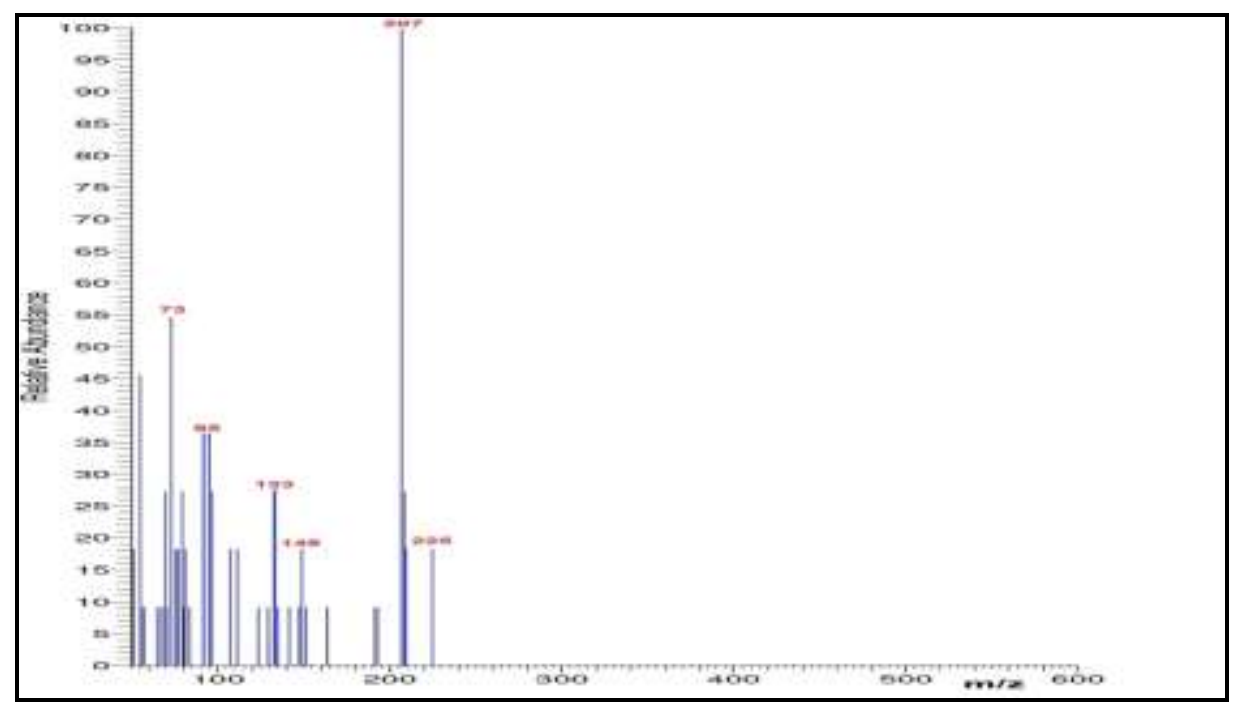

Fig.8 mass spectra of CR dye during sunlight degradation

The results suggest the degradation of dye follows the cleavage of Azo bonds $(\mathrm{N}=\mathrm{N})$ and the bonds between C-N and C-C as the result showing at value 255 and 133. Moreover, the two values that appear at 95 and 149 back to the attack of hydroxyl free radicals and substitution it on the ring of dye in acidic medium. By increasing the time of sun irradiation, the molecular weight decrease and degradation complete to formed $\mathrm{CO}_{2}$ and $\mathrm{H}_{2} \mathrm{O}$ as the following pathway: 


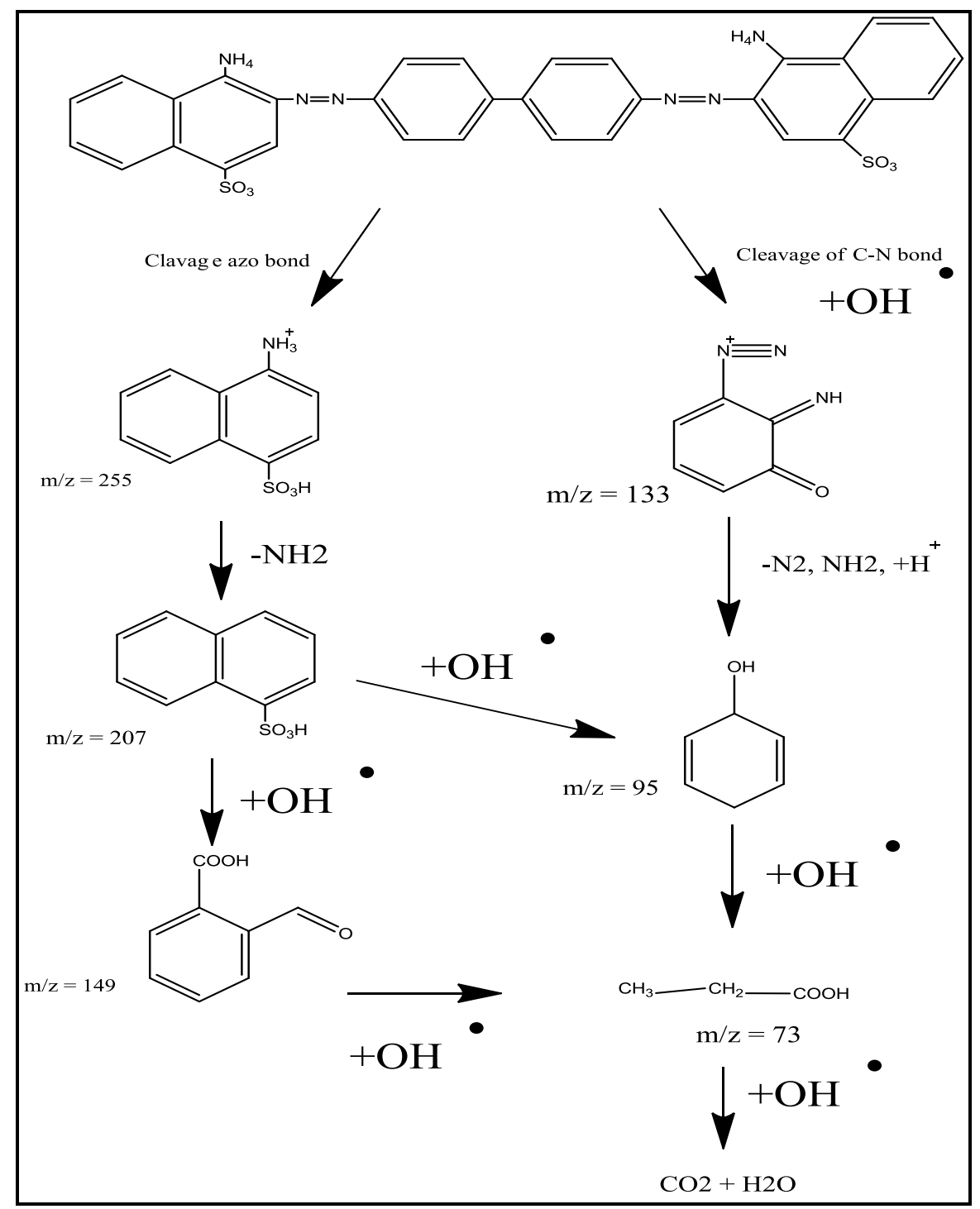

\section{Conclusion}

Visible nanophotocatalyst $\mathrm{TiO}_{2} / \mathrm{Cr}_{2} \mathrm{O}_{3}$ synthesized using photolysis method. XRD and Raman spectra proved doping $\mathrm{CdS}$ on the surface or inside the crystalline lattices of nanocompsite. Red shift to a longer wavelength visible region showed with doping $\mathrm{CdS}$ and this allows to use the nanocomposite under sunlight. Many impacts such dosage of catalyst, $\mathrm{pH}$ and irradiation time used to get the optimum results. High to dosage cause decrease the efficiency due to the agglomeration of particles while, the acidic medium gives the best result because different the charges.

\section{References}

1. R. Molinari, F. Pirillo, M. Falco, V. Loddo, L. Palmisano, Photocatalytic degradation of dyes by using a membrane reactor, Chem. Eng. Process. 43, (2004), 1103-1114.

2. S. Bilgi, C. Demir, Identification of photooxidation degradation products of C. I. Reactive Orange 16 dye by gas chromatography-mass spectrometry, Dyes Pigments 66 (2005) 69-76.

3. K.I. Konstantinou, A.A. Triantafyllos, TiO2-assisted photocatalytic degradation of azo dyes in aqueous solution: kinetic and mechanistic investigations, Appl. Catal. B: Env. 49 (2004) 1-14.

4. C. Guillard, H. Lachheb, A. Houas, M. Ksibi, E. Elaloui, J.M. Herrmann, Influence of chemical structure of dyes of $\mathrm{pH}$ and of inorganic salts on their photocatalytic degradation $\mathrm{b} \mathrm{TiO} 2$ comparison of the efficiency of powder and supported TiO2, J. Photochem. Photobiol. A: Chem. 158 (2003) 27-36. 
5. C. Hachem, F. Bocquillon, O. Zahraa, M. Bouchy, Decolourization of textile industry wastewater by the photocatalytic degradation process, Dyes Pigments 49 (2001) 117-125.

6. V. Augugliaro, C. Baiocchi, A.B. Prevot, E.G. Lopez, V. Loddo, S. Malato, G. Marci, L. Palmisano, M. Pazzi, E. Pramauro, Azo-dyes photocatalytic degradation in aqueous suspension of $\mathrm{TiO} 2$ under solar irradiation, Chemosphere 49 (2002) 1223-1230.

7. I.A. Alaton, I.A. Balcioglu, D.W. Bahnemann, Advanced oxidation of areactive dyebath effluent: comparison of O3, H2O2/UV-C and TiO2/UV-A processes, Water Res. 36 (2002) 1143-1154.

8. X.Y. Zhang, H.P. Li, X.L. Cui, Y. Lin, J. Mat. Chem. 20, 2801- 2806 (2010)

9. E.Pajootan,M.Arami,M.Rahimdokht,Ind.Eng.Chem.Res.53, 16261-16269 (2014)

10. Q. Xiang, J. Yu, M. Jaroniec, Chem. Soc. Rev. 41, 782-796 (2012)

11. C. Lin, Y. Song, L. Caoc, S. Chen, Nanoscale5, 4986-4992 (2013)

12. T. Naveen Reddy, J. Manna, R.K. Rana, ACS Appl. Mater. Inter- faces 7, 19684-19690(2015)

13. R. Bera, S. Kundu, A. Patra, ACS Appl. Mater. Interfaces 7, 13251-13259 (2015)

14. G.R. Xua, J.N. Wang, C.J. Li, Appl. Surf. Sci. 279, 103-108 (2013)

15. N. Pugazhenthiran, S. Ramkumar, P. Sathish Kumar, S. Anan-dan, MicroporousMesoporous Mater. 131, 170-176(2010)

16. T. Ochiai, A. Fujishima, J. Photochem. Photobiol.C 13,247-262 (2012).

17. A. Pandikumar, R. Ramaraj, J. Renew. Sustain. Energy 5, 043101 (2013)

18. H. Song, S. You, T. Chen, X. Jia, J. Mater. Sci. 26, 8442-8450 (2015)

19. N. Pugazhenthiran, S. Murugesan, S. Anandan, J. Hazard.Mater. 263, 541-549 (2013)

20. H. Zhao, L. Liu, J.M. Andinobc, Y. Li, J. Mater. Chem. A. 1, 8209-8216 (2013)

21. W.N. Wang, J. Park, P. Biswas, Catal. Sci. Technol. 1, 593-600 (2011)

22. Rawnaq B. Jimaa, Zaid H. Mahmoud, Farah K. Ali, Evaluation the efficiency of $\mathrm{CuFe}_{2} \mathrm{O}_{4}$ preparedphotolysis by OSD and photo degradation, EntomolApplSciLett, 2018, 5 (2): 91-100

23. Noor Sabah Al-Obaidi, Zaid Hamid Mahmoud, Ahlam Ahmed Frayyih, Anfal S. Ali, Farah K. Ali, (2018),"Evaluating the electric properties of poly aniline with doping $\mathrm{ZnO}$ and $\alpha-\mathrm{Fe}_{2} \mathrm{O}_{3}$ nanoparticles",Pharmacophore, 9(5), 61-67.

24. Mohammed A.F, Zaid H.M, Marwa S.F, Syntheses,characterization and studying TiO2/Au nanocomposite via UV-irradiation methodand its effective to degradation of methylene blue, Asian journal of chemistry, 30(5), 1124-1146, 2018.

25. T.T. Duong Vu, F. Mighri, A. Ajji, T.O. Do, Ind. Eng. Chem. Res. 53, 3888-3897(2014)

26. J. Di, S. Li, Z. Zhao, Y. Huang, Y. Jia, H. Zheng, Chem. Eng.J. 281, 60-68 (2015)

27. K.I. Konstantinou, A.A. Triantafyllos, TiO2-assisted photocatalytic degradation of azo dyes in aqueous solution: kinetic and mechanistic investigations, Appl. Catal. B: Env. 49 (2004) 1-14.

28. N. Daneshaver, D. Salari, A.R. Khataee, Photocatalytic degradation of azo dye acidic red 14 in water: investigation of the effect of operationalparameters, J. Photochem. Photobiol. A: Chem. 157 (2003) 111-11.

29. N. Daneshaver, D. Salari, A.R. Khataee, Photocatalytic degradation of azo dye acidic red 14 in water: investigation of the effect of operational parameters, J. Photochem. Photobiol. A: Chem. 157 (2003) $111-116$.

30. Guo H, Lin K, Zheng Z, Xiao F, Li S (2012) Sulfanilic acid-modified p25 $\mathrm{TiO}_{2}$ nanoparticles with improved photocatalytic degradation on Congo red under visible light. Dyes Pigm 92:1278-1284.

31. Bahnemann W, Muneer M, Haque M (2007) Titanium dioxidemediated photocatalysed degradation of few selected organic pollutants in aqueous suspensions. Catal Today 124:133-148.

32. Konstantinou I, Albanis $\mathrm{T}$ (2004) $\mathrm{TiO} 2$-assisted photocatalytic degradation of azo dyes in aqueous solution: kinetic and mechanistic investigations: a review. ApplCatal B 49:1-14 